\title{
Expression of phosphorylated elF4E-binding protein 1, but not of elF4E itself, predicts survival in male breast cancer
}

\author{
Rebecca A Millican-Slater ${ }^{1,2}$, Craig D Sayers ${ }^{3}$, Andrew M Hanby ${ }^{1,2}$ and Thomas A Hughes ${ }^{\star, 2}$ \\ ${ }^{1}$ Department of Cellular Pathology, St James's University Hospital, Leeds LS9 7TF, UK; ${ }^{2}$ School of Medicine, University of Leeds, \\ Leeds LS9 7TF, UK and ${ }^{3}$ Histopathology Department, Mid Yorkshire Hospitals NHS Trust, Dewsbury WF13 4HS, UK
}

Background: Male breast cancer is rare and treatment is based on data from females. High expression/activity of eukaryotic initiation factor 4E (elF4E) denotes a poor prognosis in female breast cancer, and the elF4E pathway has been targeted therapeutically. Eukaryotic initiation factor $4 \mathrm{E}$ activity in female breast cancer is deregulated by elF4E overexpression and by phosphorylation of its binding protein, 4E-BP1, which relieves inhibitory association between elF4E and 4E-BP1. The relevance of the elF4E pathway in male breast cancer is unknown.

Methods: We have assessed expression levels of elF4E, 4E-BP1, 4E-BP2 and phosphorylated 4E-BP1 (p4E-BP1) using immunohistochemistry in a large cohort of male breast cancers $(n=337)$ and have examined correlations with prognostic factors and survival.

Results: Neither elF4E expression nor estimated elF4E activity were associated with prognosis. However, a highly significant correlation was found between p4E-BP1 expression and disease-free survival (DFS), linking any detectable p4E-BP1 with poor survival (univariate log rank $P=0.001$; multivariate $H R 8.8, P=0.0001$ ).

Conclusions: Our data provide no support for direct therapeutic targeting of elF4E in male breast cancer, unlike in females. However, as p4E-BP1 gives powerful prognostic insights that are unrelated to elF4E function, p4E-BP1 may identify male breast cancers potentially suitable for therapies directed at the upstream kinase, mTOR.

Male breast cancer $(\mathrm{MBC})$ is a rare disease, accounting for less than $1 \%$ of all breast cancers and less than $1 \%$ of all male cancers diagnosed in the UK in 2009 (CRUK, 2010). There is relatively little research into $\mathrm{MBC}$, presumably as a result of its rarity, and much of the published work has focused on comparisons with female breast cancer (FBC). Comparisons demonstrate that $\mathrm{MBC}$ is more likely to be estrogen receptor positive ( $92 \%$ positivity $v s 78 \%$ for FBC; Ruddy and Winer, 2013), and has some differences in genetic (Johansson et al, 2011; Kornegoor et al, 2012; Piscuoglio et al, 2016), transcriptomic (Callari et al, 2011; Johansson et al, 2012) and protein expression profiles (Shaaban et al, 2012; reviewed in Deb et al, 2016). Incidence trends in terms of geographical location and impact of patient age for both diseases are broadly similar (Kreiter et al, 2014). These studies have not given insights that suggest that different treatment approaches are appropriate, either in terms of which prognostic or predictive markers might be useful, or which therapies should be used. Also, there are no prospective randomised controlled trials for MBC that could inform treatment decisions (Bratman et al, 2012). Consequently, MBC management is based on data from FBC. One key difference, however, is that the vast majority of MBC patients undergo mastectomies (Korde et al, 2010), whereas breast-conserving surgery is prevalent for FBC. It is worth noting that this difference is not based on evidence concerning treatment outcomes, rather on practical issues relating to the size of breast tissue. Adjuvant therapies, including

*Correspondence: Dr TA Hughes; E-mail: t.hughes@leeds.ac.uk

Received 18 March 2016; revised 4 May 2016; accepted 17 May 2016; published online 9 June 2016

(c) 2016 Cancer Research UK. All rights reserved 0007-0920/16 
radiotherapy (Ruddy and Winer, 2013), tamoxifen (Ribeiro and Swindell, 1992; Fogh et al, 2011) and chemotherapy (Korde et al, 2010), are essentially the same.

The eukaryotic translation initiation factor $4 \mathrm{E}$ (eIF4E) is a key component of the translational machinery and has two specific functions. Firstly, it recognises and binds to mRNA caps within the cytoplasm allowing initiation of cap-dependent translation (Sonenberg, 2008), the mechanism responsible for most protein synthesis (Gray and Wickens, 1998). Secondly, eIF4E binds to some mRNAs within the nucleus and regulates their nuclear export (Culjkovic et al, 2005, 2007). Activity of eIF4E is controlled largely by the eIF4E-binding proteins (4E-BPs), of which there are three, although only 4E-BP1 and 2 have been studied in any detail. Eukaryotic initiation factor $4 \mathrm{E}$ function is inhibited when bound by 4E-BPs (Matsuo et al, 1997), but this interaction is itself regulated by a series of sequential phosphorylations to the 4E-BPs mediated via the mTORC1 complex (Gibbons et al, 2009). Phosphorylated $4 \mathrm{E}-\mathrm{BPs}$ are unable to bind to eIF4E. Thus, eIF4E activity is defined by a subtle balance of expression levels of eIF4E and the 4E-BPs, and the phosphorylation status of the 4E-BPs (Coleman et al, 2009). Activity of eIF4E is frequently increased in a wide range of cancers (De Benedetti and Graff, 2004), resulting in enhanced translation (and potentially nuclear export) of a subset of mRNAs that contains many cancer-related transcripts. In FBC, eIF4E is frequently expressed at higher levels in breast cancers compared with normal or benign breast tissue (Kerekatte et al, 1995; Norton et al, 2004) and higher levels of eIF4E are associated with poorer prognoses (Li et al, 2002; Byrnes et al, 2006). In addition, higher levels of the phosphorylated form of 4E-BP1 (p4E-BP1) are also seen in FBC compared with normal and benign tissue (Zhou et al, 2004), and these levels are positively associated with grade, lymph node metastasis and disease recurrence (Rojo et al, 2007). Our own work has demonstrated that combined analysis of expressions of eIF4E, 4E-BP1, 4E-BP2 and p4E-BP1 predicts breast cancer survival in females and represents an estimate of eIF4E activity (Coleman et al, 2009). The influential role that eIF4E plays in neoplasia has made it an attractive anticancer drug target. Therapeutic approaches that have been explored include knockdown of eIF4E expression (Graff et al, 2007; Hong et al, 2011), blocking of eIF4E-cap binding (Assouline et al, 2009; Pettersson et al, 2011), inhibition of eIF4E phosphorylation in an effort to reduce its activity (Wheater et al, 2010), and - most commonly inhibition of mTORC1 activity leading to 4E-BP hypophosphorylation and inhibitory binding to eIF4E (Chan et al, 2005; Wazir et al, 2014). It should be noted that inhibition of mTORC1, or more generally the mTOR kinase component of this complex, clearly has anticancer influence that is independent of $4 \mathrm{E}-\mathrm{BP} 1$ through other targets of the complex (Laplante and Sabatini, 2009), and therefore this approach is in no way equivalent to direct targeting of eIF4E. Currently nothing is known about the prognostic relevance of eIF4E and the $4 \mathrm{E}-\mathrm{BPs}$ in $\mathrm{MBC}$, and there is no evidence base from which novel eIF4E-directed therapies might be considered in this disease; our aim was to perform the first investigation of the importance of these molecules in this cancer type.

\section{MATERIALS AND METHODS}

Patients and tissue microarrays. Ethical approval was obtained from Leeds (West) (ref 06/Q1205/156) and Leeds (East) Research Ethics Committees (ref 05/Q1206/136). Archival resection samples of invasive breast cancers from MBC patients $(n=337)$ and associated clinical and pathological data were collected from the United Kingdom (157; 46.6\%), Italy (50; 14.8\%), Hungary (41; $12.2 \%)$, Poland $(30 ; 9.5 \%)$, Canada $(50 ; 14.8 \%)$ and Nigeria
Table 1. Clinical and pathological features of the cohort

\begin{tabular}{|c|c|}
\hline Characteristics & $\begin{array}{c}\text { Number (\%) } \\
n=337\end{array}$ \\
\hline \multicolumn{2}{|l|}{ Histological type } \\
\hline Ductal no-special type & $275(81.6)$ \\
\hline Papillary/encysted papillary & $17(5.1)$ \\
\hline Mucinous & $11(3.3)$ \\
\hline Lobular & $3(0.9)$ \\
\hline Other special type & $5(1.5)$ \\
\hline Mixed & $8(2.4)$ \\
\hline Unknown & $8(2.4)$ \\
\hline \multicolumn{2}{|l|}{ Tumour grade } \\
\hline 1 & $44(13.1)$ \\
\hline 2 & $158(46.9)$ \\
\hline 3 & $121(35.9)$ \\
\hline Ungraded & $14(4.2)$ \\
\hline \multicolumn{2}{|l|}{ Tumour size } \\
\hline $1(<2 \mathrm{~cm})$ & $70(20.8)$ \\
\hline $2(2-5 \mathrm{~cm})$ & $65(19.3)$ \\
\hline $3(>5 \mathrm{~cm})$ & $14(4.2)$ \\
\hline Unknown & $188(55.8)$ \\
\hline \multicolumn{2}{|l|}{ LN status } \\
\hline At least 1 positive node & $112(33.2)$ \\
\hline No positive nodes & $101(30.0)$ \\
\hline Unknown & $124(36.8)$ \\
\hline \multicolumn{2}{|l|}{ ER status } \\
\hline Positive (Allred score $>2$ ) & $238(70.6)$ \\
\hline Negative & $52(15.4)$ \\
\hline Unknown & $47(13.9)$ \\
\hline \multicolumn{2}{|l|}{ PR status } \\
\hline Positive (Allred score $>2$ ) & $238(70.6)$ \\
\hline Negative & 48 (14.2) \\
\hline Unknown & $51(15.1)$ \\
\hline
\end{tabular}

(9; 2.7\%). Clinico-pathological characteristics are shown in Table 1. Survival data were available for 187 cases. Tissue microarrays (TMAs) were constructed from tissues; this process has been described in detail previously (Shaaban et al, 2012). In summary, $\mathrm{H}+\mathrm{E}$-stained tumour sections were reviewed by specialist breast consultant histopathologists (RAM-S, AMH, Dr Abeer Shaaban (Queen Elizabeth Hospital, Birmingham, UK)) in order to confirm diagnoses and select representative areas of invasive carcinoma from which TMA cores would be taken. Tissue microarrays were constructed of duplicate or triplicate $0.6 \mathrm{~mm}$ tumour cores from each individual case. Seven TMA blocks were used for the cohort, each including a perimeter wall of non-breast tissue (liver, sheep lung, placenta and brain) to minimise edge effects and to provide internal controls.

Immunohistochemistry. Immunohistochemistry was carried out as previously described (Coleman et al, 2009). In summary, $5 \mu \mathrm{m}$ sections were taken from blocks, and were deparaffinised and re-hydrated. Appropriate antigen retrieval (see below) was performed and sections were treated with $1 \%$ hydrogen peroxide-methanol to inhibit endogenous peroxide activity. Sections were stained overnight with primary antibodies (see below) diluted in antibody diluent solution (Invitrogen, Carlsbad, CA, USA). Signals were visualised using the DAB based Envision System (Dako, Glostrup, Denmark). All case TMAs, and a control TMA of FBCs, were stained for each antibody as a single batch. Female cores served as positive and negative controls. Antibodies, dilutions and antigen retrieval: eIF4E (moue monoclonal sc9976; Santa Cruz Biotechnology, Santa Cruz, CA, USA; $1: 100$; boiled for $2 \mathrm{~min}$ in a pressure cooker in antigen unmasking solution, Vector, Burlingame, CA, USA); 4E-BP1 (rabbit polyclonal 9452; 
Cell Signalling Technology (Danvers, MA, USA); 1:100; no antigen retrieval); 4E-BP2 (rabbit polyclonal 2845; Cell Signalling Technology); $1: 100 ; 12 \mathrm{~min}$ full power microwave in $\mathrm{pH} 6$ citrate buffer); p4E-BP1 Thr37/46 (rabbit polyclonal 2855; Cell Signalling Technology; $1: 25 ; 12$ min full power microwave in pH6 citrate buffer). The specificities of these antibodies have been validated previously and they have all been used successfully for immunohistochemistry in breast tissue previously (Zhou et al, 2006; Coleman et al, 2009; Satheesha et al, 2011).

Scoring and statistics. Stained TMAs were digitally scanned (Aperio, Oxford, UK), and cores were scored independently by two consultant histopathologists (RAM-S and CDS) from the same digital images. Cytoplasmic and nuclear immunoreactivity was separated and given individual scores. The scoring system incorporated scores for staining intensity in tumour cells (0 no staining, 1 weak staining, 2 moderate staining and 3 strong staining) added to scores for proportions of tumour cells staining positively ( $1<5 \%, 26-25 \%, 326-75 \%$ and $4>75 \%$ ), giving totals of either 0 or from 2 to 7 , as has been used previously for these antigens (Zhou et al, 2006; Coleman et al, 2009). Analyses were performed in SPSS (SPSS, Chicago, IL, USA) unless stated otherwise. Correlations between antigen expression scores and clinical factors were examined by calculating Spearman rho correlation coefficients. Associations with disease recurrence and survival were analysed by Kaplan-Meir survival curves and log rank tests following ROC curve analysis to dichotomise the expression scores into low and high expression appropriately. Kappa calculations were performed using Analyse-it for Excel (Microsoft, Redmond, WA, USA). All tests were two-sided.

\section{RESULTS}

eIF4E, 4E-BP1, 4E-BP2 and p4E-BP1 expression varies widely in MBC. Tissue microarrays (TMAs) containing duplicate or triplicate samples from 337 male breast tumours were stained using immunohistochemistry to analyse expression of eIF4E, 4E-BP1, $4 \mathrm{E}-\mathrm{BP} 2$ and $\mathrm{p} 4 \mathrm{E}-\mathrm{BP} 1$. Cores were scored by two independent histopathologists in terms of expression intensity and proportions of cells staining positively. To take into account the potentially different roles of these protein species in different cellular compartments (Culjkovic et al, 2006; Sonenberg, 2008), cytoplasmic and nuclear immunoreactivity were separated and given individual scores. Scores from the two histopathologists were highly concordant, demonstrating robust and reproducible scoring; quadratic weighted kappa statistics were $0.85-0.96$ for cytoplasmic scores and 0.74-0.95 for nuclear (depending on antigen; see Supplementary Table S1). Core loss, an expected and documented occurrence in TMA-based research (Parsons and Grabsch, 2009), or lack of tumour cells meant that staining was not assessable in some cases; however a mean of 2.3 cores was successfully scored for each case for each antibody. We analysed variability in scores between multiple cores representing individual tumours in order to assess potential heterogeneity within individual tumours and therefore the representative nature of TMA cores. Spearman's rho correlation coefficients for duplicate scores for each tumour and antigen were all $0.79(P<0.001)$ or over, demonstrating that there was relatively little heterogeneity in marker expression within individual tumours and that TMA-based analyses were appropriate. Having determined that inter-scorer and core-to-core variability were low, we took mean values of all the scores available for each case/antigen/subcellular location to create single scores for further analysis. Representative staining and the frequency distributions of these scores (rounded to the nearest whole number) are shown in Figure 1. The full range of expression patterns was seen for each antigen, ranging from no detectable expression to strongly expressed in more than $75 \%$ of tumour cells. The distributions of cytoplasmic and nuclear scores were broadly similar for each antigen, and expressions in the two compartments were strongly associated (Spearman's rho correlation coefficients $0.85-0.95, P<0.0008$ ), suggesting that separating the two scores gave relatively little additional information.

Expression of eIF4E correlates weakly with ER status in MBC. Associations between marker expression and established prognostic factors were examined. The factors tested were: (1) histological tumour grade (1, 2 or 3$)$; (2) tumour size (categorised as $2 \mathrm{~cm}$ or less, $>2 \mathrm{~cm}$ but $\leqslant 5 \mathrm{~cm}$, or $>5 \mathrm{~cm}$ ); (3) lymph node status (negative or positive); and (4) oestrogen receptor alpha $(\mathrm{ER} \alpha)$ status (negative (Allred 0 or 2) or positive (Allred >2)). Spearman's rho correlation coefficients $(r)$ were calculated for each potential association. The only associations with Spearman's coefficients $>0.2$, which is weak at best, were both
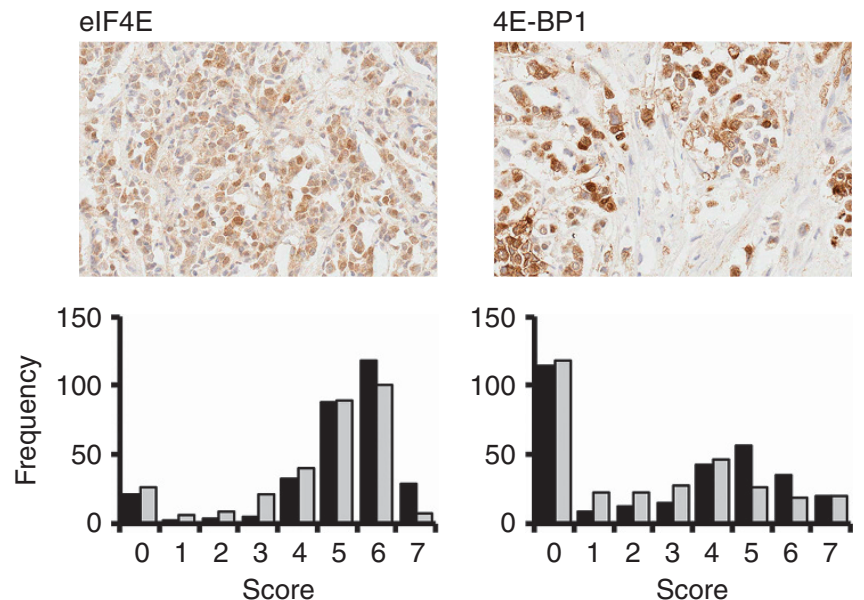

4E-BP2
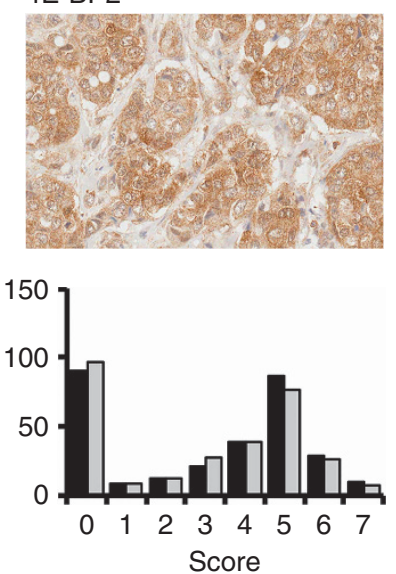

p4E-BP1
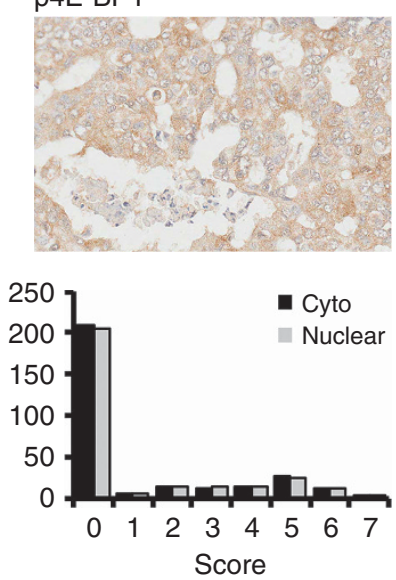

Figure 1. Male breast cancer (MBC) has a full range of expression patterns for elF4E, 4E-BP1, 4E-BP2 and p4E-BP1. Tissue microarrays containing multiple tumour cores from $337 \mathrm{MBCs}$ were stained as indicated using immunohistochemistry. Cytoplasmic and nuclear expressions in tumour cells were assessed as 0 (negative) or 2-7 (positive, increasing intensity/proportion of positive cells). Representative positive staining is shown at the top of the panel for each antigen. Images shown were scored for cytoplasmic (c) and nuclear (n) expression as follows: elF4E - c 7, n 6; 4E-BP1 - c 4, n 5; 4E-BP2 - c 5, n 0; p4E-BP1 - c 6, n 3. Frequency distributions of cytoplasmic (black) or nuclear (grey) expression across the cohort are shown below. Mean scores for each case were determined and are represented rounded to the nearest whole number. 


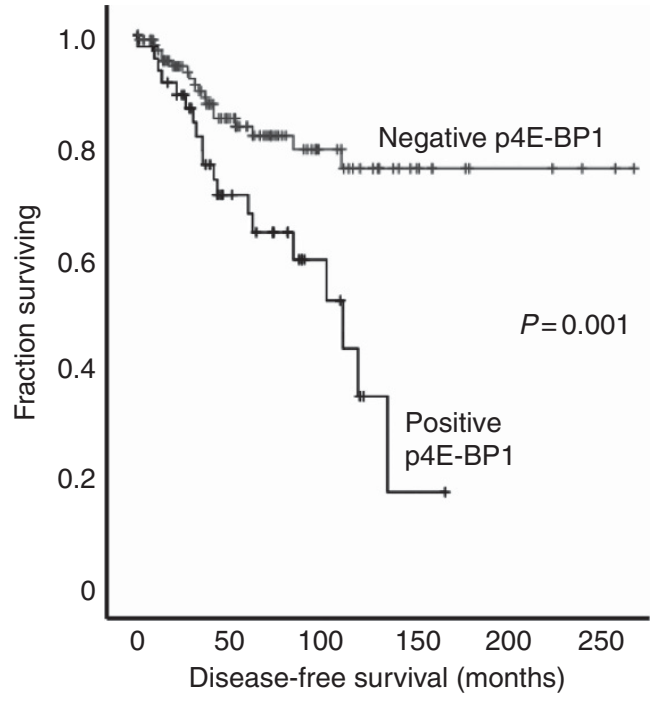

Figure 2. Expression of p4E-BP1 is significantly associated with disease-free survival in male breast cancer $(P=0.001)$. Kaplan-Meier survival analyses for patient groups with tumours with either no detectable (negative; grey line) or any detectable (positive; black line) expression of P4E-BP1.

cytoplasmic and nuclear eIF4E expression being positively associated with $\mathrm{ER} \alpha$ status $(r=0.231$ and 0.202 , respectively; $P<0.002)$

Expression of p4E-BP1, but not eIF4E, is strongly associated with MBC survival. Kaplan-Meier survival analyses were performed to determine whether expression of the markers was significantly related to DFS. Cutoffs were applied to dichotomise patients into two groups based on low or high expression of each marker. These cutoffs were defined objectively using receiver operator curve analyses (Zlobec et al, 2007) to give the best balance between sensitivity and specificity for prediction of the relevant clinical outcome (i.e. breast cancer recurrence). The cutoff values are shown in Supplementary Table S2. Kaplan-Meier survival analyses were performed and log rank tests were used to assess the significance of relationships. A stringent value of $P<0.003$ was defined as indicating significance, after Bonferroni correction for multiple tests from an initial value of $P<0.05$. Only cytoplasmic expression of $\mathrm{p} 4 \mathrm{E}-\mathrm{BP} 1$ demonstrated a significant relationship with survival (Figure 2), with patients with low p4E-BP1 expression having a longer DFS than those with high expression (215 vs 95 months, $P=0.001$ ). It is important to note that the cutoff to dichotomise $\mathrm{p} 4 \mathrm{E}-\mathrm{BP} 1$ expression was 0.83 , meaning that tumours in the two groups were those without detectable p4E-BP1 (negative) or those with any detectable expression (positive). Cytoplasmic and nuclear expression of $4 \mathrm{E}-\mathrm{BP} 1$, and - surprisingly - nuclear expression of 4E-BP2, also showed trends towards significant relationships with survival, although these fell short of our stringent significance test. Expression of eIF4E itself showed no such trend (Supplementary Table S3).

Estimated eIF4E activity is not associated with MBC survival. We have previously demonstrated in FBC that assessments of expression of these markers could be combined to estimate eIF4E activity, an estimated value that was significantly associated with survival (Coleman et al, 2009). Activity (referred to as ' $z$ ') was estimated as $X-\mathrm{BP} 1 / 4+\mathrm{pBP} 1 / 2-\mathrm{BP} 2 / 4$, where $X$ represents the eIF4E score, BP1 the 4E-BP1 score, BP2 the 4E-BP2 score and $\mathrm{pBP} 1$ the $\mathrm{p} 4 \mathrm{E}-\mathrm{BP} 1$ score. This estimate was determined for these MBC cases using the cytoplasmic scores, and receiver operator curve analysis was performed to determine a suitable cutoff to split
Table 2. Cytoplasmic p4E-BP1 is significantly associated with survival in univariate and multivariate regression analysis

\begin{tabular}{|l|c|c|c|c|}
\cline { 2 - 5 } & \multicolumn{3}{c}{ Univariate analysis } & Multivariate analysis \\
\cline { 2 - 5 } & Hazard ratio & $P$-value & Hazard ratio & $P$-value \\
\hline Cytoplasmic P4E-BP1 & 3.073 & 0.001 & 8.755 & $<0.0005$ \\
\hline Tumour size & 1.963 & 0.048 & 2.923 & 0.016 \\
\hline Tumour grade & 0.704 & 0.165 & 0.432 & 0.129 \\
\hline LN status & 1.494 & 0.326 & 4.976 & 0.018 \\
\hline ER status & 1.792 & 0.277 & 1.176 & 0.788 \\
\hline Abbreviations: ER = oestrogen receptor alpha; LN =lymph node. \\
\hline
\end{tabular}

the cohort in groups with high and low $z$ scores. Kaplan-Meier survival analyses were performed. Estimated eIF4E activity was not significantly associated with DFS (Supplementary Table S3).

Cytoplasmic p4E-BP1 is significantly associated with survival in multivariate analysis. Multivariate regression was performed to assess whether cytoplasmic expression of p4E-BP1 was an independent prognostic factor with regard to DFS. The other variables put into the model were the currently used prognostic factors of grade, tumour size, lymph node status and ER $\alpha$ status. Both cytoplasmic p4E-BP1 expression and tumour size were significantly associated with DFS on univariate and multivariate analyses, although cytoplasmic p4E-BP1 expression consistently showed the greater significance and the more informative hazard ratio (Table 2).

\section{DISCUSSION}

This study is the first in which expressions and prognostic relevance of eIF4E and the 4E-BPs have been examined in MBC. Our analysis involved one of the largest $\mathrm{MBC}$ cohorts assembled $(n=337)$ and thorough immunohistochemical analyses with multiple tissue samples per case, very robust histopathological scoring and well-validated antibodies. It is also worth noting that our work is the first in any cancer to separately investigate the prognostic worth of eIF4E and its regulatory molecules in cytoplasmic and nuclear compartments, in accordance with their different reported roles in these locations (De Benedetti and Graff, 2004; Siddiqui and Borden, 2012). We found expression in these compartments to be tightly correlated, and separate prognostic insights were not gained from the compartment analysis. Interestingly, some individual cases with prominent nuclear only or cytoplasmic only expression were noted, suggesting that subcellular regulation may take place in some circumstances; however, cases were infrequent and analysis of their common clinicopathological features was flawed on this basis. A rare precedent for separating different subcellular localisation of these molecules in cancer is, remarkably, also in the context of MBC. Nuclear and cytoplasmic distributions of p4E-BP1 have been reported previously in 56 familial MBCs, showing expression in the two compartments to be highly associated and positive in 52 and $55 \%$ of cases, respectively (slightly more than we find) (Deb et al, 2013).

Surprisingly, and in marked contrast to FBC (Coleman et al, 2009), no association was found between eIF4E expression and survival. Expression of eIF4E has been associated with prognosis in a wide range of cancers (De Benedetti and Graff, 2004), but there are specific cancers where this is not the case, for example, in acute myeloid leukaemia (Green et al, 2012) or osteosarcoma (Osborne et al, 2011). In addition, there is likely to be a publication bias against such findings, so it may be that this lack of association is 
more common than currently appreciated. Strikingly, however, we identified a strong prognostic association for p4E-BP1, with any detectable p4E-BP1 expression correlated with poor survival in both univariate and multivariate analyses (Figure 2 and Table 2). This association was far stronger than previously found in FBC (Coleman et al, 2009). 4E-BP1 phosphorylation breaks 4E-BP1's inhibitory interaction with eIF4E resulting in increased eIF4E activity (De Benedetti and Graff, 2004); therefore, one might expect that $\mathrm{p} 4 \mathrm{E}-\mathrm{BP} 1$ could only be functionally associated with prognosis through the eIF4E pathway. Yet, here we show that the wide variations in expression of eIF4E itself, or in estimated eIF4E activity, do not impact on prognosis (Supplementary Tables S2 and S3), rendering this expectation incompatible with our data. We interpret this to suggest that $\mathrm{p} 4 \mathrm{E}-\mathrm{BP} 1$ is acting as a biomarker for functionally relevant activity of the upstream kinase, the mTORC1 complex, rather than having a direct functional impact on prognosis itself. In support of this, it is well established that levels of $\mathrm{p} 4 \mathrm{E}-\mathrm{BP} 1$ correlate with mTORC1 activity in various contexts, and accordingly p4E-BP1 has frequently been used as a pharmacodynamic marker for mTORC1 activity in trials of mTORC1-targeting therapeutics (Tabernero et al, 2008; Spunt et al, 2011).

The kinase within the mTORC1 complex is mTOR, upregulation of which is associated with development of many cancers (Shaw and Cantley, 2006). The mTORC1 complex acts on a large number of different molecular substrates (Laplante and Sabatini, 2009; Hsu et al, 2011), although the functional importance of two have been studied in considerably more detail than the others with regard to cancer: 4E-BP1 and S6 kinase 1 (S6K1). In MBC we believe that $4 \mathrm{E}-\mathrm{BP} 1$ may not be a functionally relevant substrate; therefore, it seems likely that deregulated mTOR acts at least in part through S6K1 and its downstream effectors. Phosphorylated (activated) S6K1 can induce oncogenic increases in overall protein translation, and changes in sterol, lipid and mitochondrial metabolism via a variety of complex signalling pathways (Alayev and Holz, 2013). Expression levels of both eIF4E and mTOR have been noted in a previous analysis of gene expression profiles in MBC $(n=37)$ as compared with FBC (Callari et al, 2011). Both proteins were found to be more highly expressed in $\mathrm{MBC}$ than in FBC, and the authors commented that the eIF4E pathway may therefore present an attractive therapeutic target in MBC. Our findings impact on this suggestion, in that we find eIF4E itself to be unrelated to prognosis, while we infer that mTOR activity within the mTORC1 complex may well relate to prognosis. Thus, our data do not support use of therapies directed at eIF4E itself, such as knockdown of eIF4E expression (Graff et al, 2007; Hong et al, 2011), or function (Assouline et al, 2009; Wheater et al, 2010; Pettersson et al, 2011), but do support potential use of therapies directed at the upstream kinase, mTOR.

These findings may delineate potential differences in appropriate treatments between FBC and MBCs. For example, the eIF4E-directed therapies LY2275796 (anti-sense oligonucleotides directed against eIF4E) and ribavirin (which reduces eIF4Edependent translation) have shown some promise in preclinical or clinical trials (Hong et al, 2011; Pettersson et al, 2015), and are undergoing evaluation for $\mathrm{FBC}$. Our data suggest that these may have limited efficacy in MBC since eIF4E activity appears relatively unimportant in determining prognosis in this disease. However, by contrast, the growing list of therapies targeting mTOR (Sun, 2013), such as everolimus or temsirolimus that have already shown promise in FBC trials (Baselga et al, 2012; Wolff et al, 2013), may well be suitable therapies in both female and male cancers. Interestingly, there is a single case report describing a favourable response of an MBC patient to temsirolimus (Katayama et al, 2013), but unfortunately it seems unlikely that an MBC trial will take place due to the rarity of the disease overall. A further issue would be that fewer than $50 \%$ of MBC cases expressed detectable
p4E-BP1 in our data (Figure 1), and therefore only a minority may potentially be suitable for this approach. Nevertheless, we conclude that mTOR-targeted therapies may be worth considering in $\mathrm{p} 4 \mathrm{E}$ BP1-positive MBC.

\section{ACKNOWLEDGEMENTS}

We thank the national and international investigators who contributed samples and data to the MBC cohort, and Dr Abeer Shaaban (Queen Elizabeth Hospital, Birmingham, UK) and Prof. Valerie Speirs (University of Leeds), who assembled the cohort. Thanks also to Prof. Speirs for providing the tissue and data through a material transfer agreement.

\section{CONFLICT OF INTEREST}

The authors declare no conflict of interest.

\section{REFERENCES}

Alayev A, Holz MK (2013) mTOR signaling for biological control and cancer. J Cell Physiol 228(8): 1658-1664.

Assouline S, Culjkovic B, Cocolakis E, Rousseau C, Beslu N, Amri A, Caplan S, Leber B, Roy DC, Miller Jr. WH, Borden KL (2009) Molecular targeting of the oncogene eIF4E in acute myeloid leukemia (AML): a proof-of-principle clinical trial with ribavirin. Blood 114(2): 257-260.

Baselga J, Campone M, Piccart M, Burris 3rd HA, Rugo HS, Sahmoud T, Noguchi S, Gnant M, Pritchard KI, Lebrun F, Beck JT, Ito Y, Yardley D, Deleu I, Perez A, Bachelot T, Vittori L, Xu Z, Mukhopadhyay P, Lebwohl D, Hortobagyi GN (2012) Everolimus in postmenopausal hormone-receptor-positive advanced breast cancer. N Engl J Med 366(6): 520-529.

Bratman SV, Kapp DS, Horst KC (2012) Evolving trends in the initial locoregional management of male breast cancer. Breast 21(3): 296-302.

Byrnes K, White S, Chu Q, Meschonat C, Yu H, Johnson LW, Debenedetti A, Abreo F, Turnage RH, McDonald JC, Li BD (2006) High eIF4E, VEGF, and microvessel density in stage I to III breast cancer. Ann Surg 243(5): 684-690discussion 691-692.

Callari M, Cappelletti V, De Cecco L, Musella V, Miodini P, Veneroni S, Gariboldi M, Pierotti MA, Daidone MG (2011) Gene expression analysis reveals a different transcriptomic landscape in female and male breast cancer. Breast Cancer Res Treat 127(3): 601-610.

Chan S, Scheulen ME, Johnston S, Mross K, Cardoso F, Dittrich C, Eiermann W, Hess D, Morant R, Semiglazov V, Borner M, Salzberg M, Ostapenko V, Illiger HJ, Behringer D, Bardy-Bouxin N, Boni J, Kong S, Cincotta M, Moore L (2005) Phase II study of temsirolimus (CCI-779), a novel inhibitor of mTOR, in heavily pretreated patients with locally advanced or metastatic breast cancer. J Clin Oncol 23(23): 5314-5322.

Coleman LJ, Peter MB, Teall TJ, Brannan RA, Hanby AM, Honarpisheh H, Shaaban AM, Smith L, Speirs V, Verghese ET, McElwaine JN, Hughes TA (2009) Combined analysis of eIF4E and 4E-binding protein expression predicts breast cancer survival and estimates eIF4E activity. $\mathrm{Br} J$ Cancer 100(9): 1393-1399.

CRUK (2010) Breast Cancer Incidence Statistics. Available at http:// www.cancerresearchuk.org/health-professional/cancer-statistics.

Culjkovic B, Topisirovic I, Borden KL (2007) Controlling gene expression through RNA regulons: the role of the eukaryotic translation initiation factor eIF4E. Cell Cycle 6(1): 65-69.

Culjkovic B, Topisirovic I, Skrabanek L, Ruiz-Gutierrez M, Borden KL (2005) eIF4E promotes nuclear export of cyclin D1 mRNAs via an element in the 3'UTR. J Cell Biol 169(2): 245-256.

Culjkovic B, Topisirovic I, Skrabanek L, Ruiz-Gutierrez M, Borden KL (2006) eIF4E is a central node of an RNA regulon that governs cellular proliferation. J Cell Biol 175(3): 415-426. 
De Benedetti A, Graff JR (2004) eIF-4E expression and its role in malignancies and metastases. Oncogene 23(18): 3189-3199.

Deb S, Do H, Byrne D, Jene N, kConFab I, Dobrovic A, Fox SB (2013) PIK3CA mutations are frequently observed in BRCAX but not BRCA2-associated male breast cancer. Breast Cancer Res 15(4): R69.

Deb S, Lakhani SR, Ottini L, Fox SB (2016) The cancer genetics and pathology of male breast cancer. Histopathology 68(1): 110-118.

Fogh S, Hirsch AE, Langmead JP, Goldberg SI, Rosenberg CL, Taghian AG, Powell SN, Kachnic LA (2011) Use of tamoxifen with postsurgical irradiation may improve survival in estrogen and progesterone receptor-positive male breast cancer. Clin Breast Cancer 11(1): 39-45.

Gibbons JJ, Abraham RT, Yu K (2009) Mammalian target of rapamycin: discovery of rapamycin reveals a signaling pathway important for normal and cancer cell growth. Semin Oncol 36(Suppl 3): S3-S17.

Graff JR, Konicek BW, Vincent TM, Lynch RL, Monteith D, Weir SN, Schwier P, Capen A, Goode RL, Dowless MS, Chen Y, Zhang H, Sissons S, Cox K, McNulty AM, Parsons SH, Wang T, Sams L, Geeganage S, Douglass LE, Neubauer BL, Dean NM, Blanchard K, Shou J, Stancato LF, Carter JH, Marcusson EG (2007) Therapeutic suppression of translation initiation factor eIF4E expression reduces tumor growth without toxicity. $J$ Clin Invest 117(9): 2638-2648.

Gray NK, Wickens M (1998) Control of translation initiation in animals. Annu Rev Cell Dev Biol 14: 399-458.

Green AS, Grabar S, Tulliez M, Park S, Al-Nawakil C, Chapuis N, Jacque N, Willems L, Azar N, Ifrah N, Dreyfus F, Lacombe C, Mayeux P, Bouscary D, Tamburini J (2012) The eukaryotic initiating factor 4E protein is overexpressed, but its level has no prognostic impact in acute myeloid leukaemia. Br J Haematol 156(4): 547-550.

Hong DS, Kurzrock R, Oh Y, Wheler J, Naing A, Brail L, Callies S, Andre V, Kadam SK, Nasir A, Holzer TR, Meric-Bernstam F, Fishman M, Simon G (2011) A phase 1 dose escalation, pharmacokinetic, and pharmacodynamic evaluation of eIF-4E antisense oligonucleotide LY2275796 in patients with advanced cancer. Clin Cancer Res 17(20): 6582-6591.

Hsu PP, Kang SA, Rameseder J, Zhang Y, Ottina KA, Lim D, Peterson TR, Choi Y, Gray NS, Yaffe MB, Marto JA, Sabatini DM (2011) The mTOR-regulated phosphoproteome reveals a mechanism of mTORC1-mediated inhibition of growth factor signaling. Science 332(6035): 1317-1322.

Johansson I, Nilsson C, Berglund P, Lauss M, Ringner M, Olsson H, Luts L, Sim E, Thorstensson S, Fjallskog ML, Hedenfalk I (2012) Gene expression profiling of primary male breast cancers reveals two unique subgroups and identifies N-acetyltransferase-1 (NAT1) as a novel prognostic biomarker. Breast Cancer Res 14(1): R31.

Johansson I, Nilsson C, Berglund P, Strand C, Jonsson G, Staaf J, Ringner M, Nevanlinna H, Barkardottir RB, Borg A, Olsson H, Luts L, Fjallskog ML, Hedenfalk I (2011) High-resolution genomic profiling of male breast cancer reveals differences hidden behind the similarities with female breast cancer. Breast Cancer Res Treat 129(3): 747-760.

Katayama K, Yamagishi J, Kashiwagi B (2013) [A case of male breast cancer for which mTOR inhibitor was effective with advanced renal cancer]. Gan to kagaku ryoho Cancer Chemother 40(3): 365-369.

Kerekatte V, Smiley K, Hu B, Smith A, Gelder F, De Benedetti A (1995) The proto-oncogene/translation factor eIF4E: a survey of its expression in breast carcinomas. Int J Cancer 64(1): 27-31.

Korde LA, Zujewski JA, Kamin L, Giordano S, Domchek S, Anderson WF, Bartlett JM, Gelmon K, Nahleh Z, Bergh J, Cutuli B, Pruneri G, McCaskill-Stevens W, Gralow J, Hortobagyi G, Cardoso F (2010) Multidisciplinary meeting on male breast cancer: summary and research recommendations. J Clin Oncol 28(12): 2114-2122.

Kornegoor R, Moelans CB, Verschuur-Maes AH, Hogenes MC, de Bruin PC, Oudejans JJ, Marchionni L, van Diest PJ (2012) Oncogene amplification in male breast cancer: analysis by multiplex ligation-dependent probe amplification. Breast Cancer Res Treat 135(1): 49-58.

Kreiter E, Richardson A, Potter J, Yasui Y (2014) Breast cancer: trends in international incidence in men and women. Br J Cancer 110(7): 1891-1897.

Laplante M, Sabatini DM (2009) mTOR signaling at a glance. J Cell Sci 122(Pt 20): 3589-3594.

Li BD, Gruner JS, Abreo F, Johnson LW, Yu H, Nawas S, McDonald JC, DeBenedetti A (2002) Prospective study of eukaryotic initiation factor $4 \mathrm{E}$ protein elevation and breast cancer outcome. Ann Surg 235(5): 732-738; discussion 738-9.
Matsuo H, Li H, McGuire AM, Fletcher CM, Gingras AC, Sonenberg N, Wagner G (1997) Structure of translation factor eIF4E bound to m7GDP and interaction with 4E-binding protein. Nat Struct Biol 4(9): 717-724.

Norton KS, McClusky D, Sen S, Yu H, Meschonat C, Debenedetti A, Li BD (2004) TLK1B is elevated with eIF4E overexpression in breast cancer. J Surg Res 116(1): 98-103.

Osborne TS, Ren L, Healey JH, Shapiro LQ, Chou AJ, Gorlick RG, Hewitt SM, Khanna C (2011) Evaluation of eIF4E expression in an osteosarcomaspecific tissue microarray. J Pediatr Hematol/Oncol 33(7): 524-528.

Parsons M, Grabsch H (2009) How to make tissue microarrays. Diagn Histopathol 15(3): 142-150.

Pettersson F, Del Rincon SV, Emond A, Huor B, Ngan E, Ng J, Dobocan MC, Siegel PM, Miller WH Jr (2015) Genetic and pharmacologic inhibition of eIF4E reduces breast cancer cell migration, invasion, and metastasis. Cancer Res 75(6): 1102-1112.

Pettersson F, Yau C, Dobocan MC, Culjkovic-Kraljacic B, Retrouvey H, Puckett R, Flores LM, Krop IE, Rousseau C, Cocolakis E, Borden KL, Benz CC, Miller WH Jr (2011) Ribavirin treatment effects on breast cancers overexpressing eIF4E, a biomarker with prognostic specificity for luminal B-type breast cancer. Clin Cancer Res 17(9): 2874-2884.

Piscuoglio S, Ng CK, Murray MP, Guerini-Rocco E, Martelotto LG, Geyer FC, Bidard FC, Berman S, Fusco N, Sakr RA, Eberle C, De Mattos-Arruda L, Macedo GS, Akram M, Baslan T, Hicks J, King TA, Brogi E, Norton L, Weigelt B, Hudis CA, Reis-Filho JS (2016) The genomic landscape of male breast cancers. Clin Cancer Res; e-pub ahead of print 9 March 2016; doi:10.1158/1078-0432.CCR-15-2840.

Ribeiro G, Swindell R (1992) Adjuvant tamoxifen for male breast cancer (MBC). Br J Cancer 65(2): 252-254.

Rojo F, Najera L, Lirola J, Jimenez J, Guzman M, Sabadell MD, Baselga J, Ramon y Cajal S (2007) 4E-binding protein 1, a cell signaling hallmark in breast cancer that correlates with pathologic grade and prognosis. Clin Cancer Res 13(1): 81-89.

Ruddy KJ, Winer EP (2013) Male breast cancer: risk factors, biology, diagnosis, treatment, and survivorship. Ann Oncol 24(6): 1434-1443.

Satheesha S, Cookson VJ, Coleman LJ, Ingram N, Madhok B, Hanby AM, Suleman CA, Sabine VS, Macaskill EJ, Bartlett JM, Dixon JM, McElwaine JN, Hughes TA (2011) Response to mTOR inhibition: activity of eIF4E predicts sensitivity in cell lines and acquired changes in eIF4E regulation in breast cancer. Mol Cancer 10: 19.

Shaaban AM, Ball GR, Brannan RA, Cserni G, Benedetto AD, Dent J, Fulford L, Honarpisheh H, Jordan L, Jones JL, Kanthan R, Maraqa L, Litwiniuk M, Mottolese M, Pollock S, Provenzano E, Quinlan PR, Reall G, Shousha S, Stephens M, Verghese ET, Walker RA, Hanby AM, Speirs V (2012) A comparative biomarker study of 514 matched cases of male and female breast cancer reveals gender-specific biological differences. Breast Cancer Res Treat 133(3): 949-958.

Shaw RJ, Cantley LC (2006) Ras, PI(3)K and mTOR signalling controls tumour cell growth. Nature 441(7092): 424-430.

Siddiqui N, Borden KL (2012) mRNA export and cancer. Wiley interdiscip Rev RNA 3(1): 13-25.

Sonenberg N (2008) eIF4E, the mRNA cap-binding protein: from basic discovery to translational research. Biochem Cell Biol 86(2): 178-183.

Spunt SL, Grupp SA, Vik TA, Santana VM, Greenblatt DJ, Clancy J, Berkenblit A, Krygowski M, Ananthakrishnan R, Boni JP, Gilbertson RJ (2011) Phase I study of temsirolimus in pediatric patients with recurrent/ refractory solid tumors. J Clin Oncol 29(21): 2933-2940.

Sun SY (2013) mTOR kinase inhibitors as potential cancer therapeutic drugs. Cancer Lett 340(1): 1-8.

Tabernero J, Rojo F, Calvo E, Burris H, Judson I, Hazell K, Martinelli E, Ramon y Cajal S, Jones S, Vidal L, Shand N, Macarulla T, Ramos FJ, Dimitrijevic S, Zoellner U, Tang P, Stumm M, Lane HA, Lebwohl D, Baselga J (2008) Dose- and schedule-dependent inhibition of the mammalian target of rapamycin pathway with everolimus: a phase I tumor pharmacodynamic study in patients with advanced solid tumors. J Clin Oncol 26(10): 1603-1610.

Wazir U, Wazir A, Khanzada ZS, Jiang WG, Sharma AK, Mokbel K (2014) Current state of mTOR targeting in human breast cancer. Cancer Genomics Proteomics 11(4): 167-174.

Wheater MJ, Johnson PW, Blaydes JP (2010) The role of MNK proteins and eIF4E phosphorylation in breast cancer cell proliferation and survival. Cancer Biol Ther 10(7): 728-735.

Wolff AC, Lazar AA, Bondarenko I, Garin AM, Brincat S, Chow L, Sun Y, Neskovic-Konstantinovic Z, Guimaraes RC, Fumoleau P, Chan A, 
Hachemi S, Strahs A, Cincotta M, Berkenblit A, Krygowski M, Kang LL, Moore L, Hayes DF (2013) Randomized phase III placebo-controlled trial of letrozole plus oral temsirolimus as first-line endocrine therapy in postmenopausal women with locally advanced or metastatic breast cancer. J Clin Oncol 31(2): 195-202.

Zhou S, Wang GP, Liu C, Zhou M (2006) Eukaryotic initiation factor 4E (eIF4E) and angiogenesis: prognostic markers for breast cancer. BMC Cancer 6: 231.

Zhou X, Tan M, Stone Hawthorne V, Klos KS, Lan KH, Yang Y, Yang W, Smith TL, Shi D, Yu D (2004) Activation of the Akt/mammalian target of rapamycin/4E-BP1 pathway by ErbB2 overexpression predicts tumor progression in breast cancers. Clin Cancer Res 10(20): 6779-6788.

Zlobec I, Steele R, Terracciano L, Jass JR, Lugli A (2007) Selecting immunohistochemical cut-off scores for novel biomarkers of progression and survival in colorectal cancer. J Clin Pathol 60(10): 1112-1116.

This work is published under the standard license to publish agreement. After 12 months the work will become freely available and the license terms will switch to a Creative Commons AttributionNonCommercial-Share Alike 4.0 Unported License.

Supplementary Information accompanies this paper on British Journal of Cancer website (http://www.nature.com/bjc) 